\title{
Validation of the All Wales Covid-19 Risk Assessment Tool in Practice:
}

\author{
Comparing individual outcomes with self-perceived risk in a sample of Black, Asian \\ and Ethnic Minority health care professionals
}

\section{ABSTRACT}

Background: The All-Wales Covid-19 Risk Assessment tool (WRA) was developed to support managers in undertaking individual risk assessments for employees in public facing work settings, and put in place appropriate mitigation. Although a tool for all employees, it's development was prompted in part by the observation that Covid-19 was disproportionately affecting Black, Asian and Minority Ethnic (BAME) employees, particularly those in health and social care settings. This simple, self-administered tool estimates an individual's risk of severe Covid-19 disease by scoring personal risk factors, based on those previously identified in the emerging literature. The aim of this study was to assess the performance of this tool, by measuring concordance between an individual respondants self perceived risk and the risk indicated by the tool in a sample of healthcare professionals.

\section{Methods:}

The WRA was distributed amongst BAME healthcare professionals around Wales, UK with additional questions to understand participant concordance with the risk stratification from the tool. Statistical analyses were applied to establish the degree of concordance. The initial survey was followed by a more widespread survey across Wales where the sample size of the respondents was 3728

\section{Results:}

A total of 136 participants responses were included in the analyses. The majority of participants were below 50 years of age (median age, range), male, and of BAME ethnicity. The weighted kappa coefficient indicated significant concordance between the tool outcome and respondent's self perceived risk $(k=)$. Younger respondents considered themselves at lower risk, which was correctly predicted by the tool. The association between risk tool outcome and self-perceived risk was not affected by participant characteristic.

Of the larger Welsh cohort of 3728 respondents, 93.8\% felt that the tool correctly identified their risk and was in concordance with their own risk perception.

\section{Conclusions:}

There was a high level of concordance between the tool user's self-perceived risk and risk assessment tool outcome. Where there was disagreement, selfperception of risk was lower than that of the tool, indicating a more precautionary approach taken by the tool. The high concordance provides user confidence that the All Wales Covid-19 risk assessment tool is likely to provide a correct risk stratification and mitigation strategies in this occupational group.

\section{Keywords}

COVID-19, Risk Assessment Tool; BAME healthcare professionals
Archit Singhal ${ }^{1}$, Alan $\mathrm{R}$ Abraham $^{2}$, Parag Singhal ${ }^{3}$, Dhananjay Raje ${ }^{4} \&$ Keshav Singhal ${ }^{5}$

\section{Imperial College School of Medicine, UK \\ 2 University of Bristol, UK 3 University Hospital, Bristol, UK \\ 4 MD Biosystems, Pune, India \\ 5 Princess of Wales Hospital, \\ Bridgend, Wales, UK}

Correspondence to; paragnsinghal@yahoo.co.uk

Cite as; Singhal, A., Abraham,A.R., Singhal, P., Raje, D., Singhal, K. (2022) Validation of the all Wales Covid-19 risk assessment tool in practice. The Physician vol7; Issue 2: epub 24.01.22 DOI

https://doi.org/10.38192/1.7.2.6

Article Information

Submitted 28.12.21

Pre-print 24.01.22

ISSN 2732-513X (Print)

ISSN 2732 - 5148 (Online) 


\section{INTRODUCTION}

Since December 2019, the severe acute respiratory syndrome 2 (SARS CoV 2) pandemic has claimed the lives of nearly 1.5 million people worldwide. The UK has been one of the worst affected countries within Europe based on a $109 \%$ increase in weekly excess deaths at its peak ${ }^{1}$. Only Spain possessed a greater increase of $155 \%{ }^{1}$. Risk factors including older age, ethnicity, male sex, and geographical area have been associated with an increased risk of contracting the infection, experiencing more severe symptoms, and higher death rates ${ }^{2}$.

In the UK people of Black, Asian, and Minority Ethnic (BAME) origin were identified to have a greater risk of both contracting COVID-19 and disease mortality early in the course of the pandemic with the majority of healthcare workers who died, coming from these backgrounds ${ }^{3,4}$. The Office of National Statistics ${ }^{3,4}$ figures revealed that highest age-standardised death rate was observed in black ethnicities, who were approximately four times more likely to die than their white counterparts. After adjusting for age, deprivation, household composition, socioeconomic status and geographical factors, this risk remained with people of Bangladeshi and Pakistani ethnic origins nearly twice as likely to die compared to people identifying as White British ${ }^{3,4}$. Furthermore, people of Chinese, Indian, Mixed and other ethnicities had between $10-50 \%$ higher risk of death when compared to White British ${ }^{3,4}$. Other studies corroborated this trend ${ }^{5,6}$.

Due to this disproportionate impact on the BAME health care professionals, the First Minister of Wales set up an advisory committee in April 2020 to support the Chief Medical Officer and Welsh Government to help better understand the risk faced by BAME individuals and thus to subsequently protect them. This led to the development of the All Wales COVID-19 risk assessment tool (WRA) ${ }^{7}$ which was the first such tool developed by any Nation of the UK.

The Welsh risk assessment group started with the objective of developing a simple to use and selfadministered risk tool taking into account the known risk factors from various large studies conducted by $\operatorname{ICNARC}^{8}$, ISARIC ${ }^{9}$, ONS ${ }^{4}$ and from a multitude of other publications. The committee's hypothesis was that, apart from age and sex, it was the clustering of various comorbidities which predisposed an individual to the risk of developing severe COVID-19 disease, rather than any single risk factor irrespective of the severity. Each comorbidity was assigned a simple risk score of one point whereas advancing age was scored higher. This study seeks to ascertain the concordance between an individual's risk assessment from the tool and their own perception of their risk of getting severe COVID-19 disease.

\section{METHODS}

Once the WRA had been finalised, an online version was developed ${ }^{10}$ and cascaded to various BAME origin healthcare professionals Their response were captured through an online submission in a CSV file. A similar online version was made available by the Welsh Government to all their NHS and Social care, Education, Police, Welsh Government employees, Business, care Homes etc ${ }^{11}$ through the electronic staff records and e-learning Wales platform.

To understand these individual perceptions of the All-Wales tool, the following question were included after the risk assessment questions:

1. Accurately estimates your risk of getting severe COVID-19 disease?

2. Overestimates your risk?

3. Underestimates your risk?

\section{Statistical methods}

The description for all the respondent's characteristics (factors) was obtained in terms of frequencies and percentages. The association between each factor and respondent's feedback was determined using Pearson's Chi-square test. The agreement between the risk stratification by tool and respondent's feedback was obtained using Weighted Kappa Coefficient. Further, the association between demographic characteristics and risk categorization for respondents in agreement with tool outcome was determined using Pearson's Chi-square test. This revealed the perception of respondents about the risk in different age categories as well as between gender types. The analyses were performed using R-3.4.3 and using stats and irr libraries and the statistical significance was set at $5 \%$ level. 


\section{RESULTS}

A total of 154 responses were obtained out of which 2 were excluded from the study due to incorrect demographic data, thus leaving 152 respondents. Further, 16 individuals were excluded due to lack of feedback on risk assessment tool; thus, a sample size of 136 was considered for downstream analysis (Figure 1).

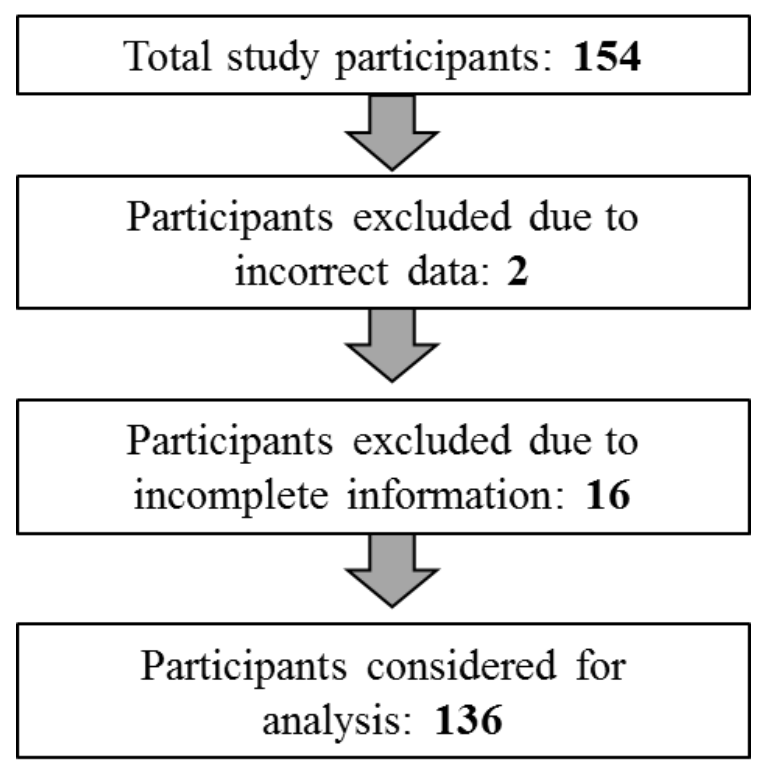

Figure 1: Sample selection flow chart 


\begin{tabular}{|c|c|c|c|}
\hline \multicolumn{2}{|l|}{ Characteristics } & \multirow{2}{*}{$\begin{array}{c}\text { Number } \\
84\end{array}$} & \multirow{2}{*}{$\begin{array}{l}\text { \% } \\
55.26 \%\end{array}$} \\
\hline \multirow{4}{*}{ Age category (years) } & $<50$ & & \\
\hline & $50-59$ & 43 & $28.29 \%$ \\
\hline & $60-69$ & 20 & $13.16 \%$ \\
\hline & $70-79$ & 5 & $3.29 \%$ \\
\hline \multirow{2}{*}{ Sex } & Female & 53 & $34.87 \%$ \\
\hline & Male & 99 & $65.13 \%$ \\
\hline Ethnicity & Yes (BAME) & 134 & $88.16 \%$ \\
\hline Diabetes Mellitus & Yes & 35 & $23.03 \%$ \\
\hline Cardiovascular disease & Yes & 51 & $33.55 \%$ \\
\hline Lung disease & Yes & 18 & $11.84 \%$ \\
\hline Kidney disease & Yes & 7 & $4.61 \%$ \\
\hline Thalassemia disease & Yes & 16 & $10.53 \%$ \\
\hline Obesity & Yes & 65 & $42.76 \%$ \\
\hline Family history & Yes & 6 & $3.95 \%$ \\
\hline \multirow{4}{*}{ Work place setting } & Community care & 29 & $19.08 \%$ \\
\hline & Primary care & 30 & $19.74 \%$ \\
\hline & Secondary care - Non AGP & 37 & $24.34 \%$ \\
\hline & Secondary care - AGP & 56 & $36.84 \%$ \\
\hline
\end{tabular}

Table 1: Demographics $(n=136)$.

*Obtained using Pearson's Chi-square test; NS: Not significant

The distribution of 152 individuals according to their demographic characteristics, co-morbidities and work place settings are given in Table 1. Individuals were most frequently male (84, 55.3\%), and aged $<50$ years. $134(88.2 \%)$ respondents classified themselves as BAME. The data on comorbidities revealed that $35(23.03 \%)$ respondents had diabetes mellitus, $51(33.55 \%)$ had cardiovascular disease, $18(11.84 \%)$ had lung disease, 7 (4.61\%) and $16(10.53 \%)$ individuals had kidney disease and thalassemia disease respectively. The proportion of obese cases was $65(42.76 \%)$. The distribution of subjects as per work place setting showed that maximum i.e. $56(36.84 \%)$ were from secondary care - AGP, followed by 37 (24.34\%) from secondary care - non-AGP, while 30 (19.74\%) and $29(19.08 \%)$ were from primary and community care units respectively. 


\begin{tabular}{|c|c|c|c|c|c|}
\hline \multirow[b]{2}{*}{ Characteristics } & \multirow[b]{2}{*}{ Levels } & \multicolumn{3}{|c|}{ Respondent's feedback } & \multirow[b]{2}{*}{ P-value* } \\
\hline & & $\begin{array}{c}\text { Correct } \\
(\mathrm{n}=111)\end{array}$ & $\begin{array}{c}\text { Underestimate } \\
(\mathrm{n}=12)\end{array}$ & $\begin{array}{c}\text { Overestimate } \\
(\mathrm{n}=13)\end{array}$ & \\
\hline \multirow{4}{*}{$\begin{array}{l}\text { Age category (in } \\
\text { years) }\end{array}$} & $<50$ & $61(54.95)$ & $10(83.33)$ & $4(30.77)$ & \multirow{4}{*}{$\begin{array}{r}0.1033 \\
\text { (NS) }\end{array}$} \\
\hline & $50-59$ & $34(30.63)$ & $2(16.67)$ & $5(38.46)$ & \\
\hline & $60-69$ & $12(10.81)$ & $0(0)$ & $430.77)$ & \\
\hline & $70-79$ & $4(3.60)$ & $0(0)$ & $0(0)$ & \\
\hline \multirow{2}{*}{ Sex } & Female & $39(35.13)$ & $7(58.33)$ & $2(15.38)$ & \multirow{2}{*}{$\begin{array}{r}0.0802 \\
\text { (NS) }\end{array}$} \\
\hline & Male & $72(64.87)$ & $5(41.67)$ & $11(84.61)$ & \\
\hline $\begin{array}{l}\text { Ethnicity } \\
\text { (BAME) }\end{array}$ & Yes & $100(90.09)$ & $10(83.33)$ & $13(100.0)$ & $\begin{array}{r}0.3515 \\
(\mathrm{NS}) \\
\end{array}$ \\
\hline $\begin{array}{l}\text { Diabetes } \\
\text { Mellitus }\end{array}$ & Yes & $25(22.52)$ & $4(33.33)$ & $1(7.69)$ & $\begin{array}{r}0.2920 \\
(\mathrm{NS}) \\
\end{array}$ \\
\hline $\begin{array}{l}\text { Cardiovascular } \\
\text { disease }\end{array}$ & Yes & $39(35.13)$ & $4(33.33)$ & $3(23.07)$ & $\begin{array}{r}0.6848 \\
(\mathrm{NS})\end{array}$ \\
\hline Lung disease & Yes & $13(11.72)$ & $1(8.33)$ & $1(7.69)$ & $\begin{array}{r}0.8654 \\
(\mathrm{NS}) \\
\end{array}$ \\
\hline Kidney disease & Yes & $3(2.70)$ & $2(16.67)$ & $1(7.69)$ & $\begin{array}{r}0.0681 \\
(\mathrm{NS})\end{array}$ \\
\hline $\begin{array}{l}\text { Thalassemia } \\
\text { disease }\end{array}$ & Yes & $8(7.21)$ & $3(25.0)$ & $2(15.38)$ & $\begin{array}{r}0.1038 \\
(\mathrm{NS}) \\
\end{array}$ \\
\hline Obesity & Yes & $42(37.83)$ & $8(66.67)$ & $8(61.54)$ & $\begin{array}{r}0.1161 \\
(\mathrm{NS}) \\
\end{array}$ \\
\hline Family history & Yes & $4(3.60)$ & $1(8.33)$ & $0(0)$ & $\begin{array}{r}0.5399 \\
(\mathrm{NS}) \\
\end{array}$ \\
\hline \multirow{4}{*}{$\begin{array}{l}\text { Work place } \\
\text { setting }\end{array}$} & Community care & $20(18.02)$ & $2(16.67)$ & $4(30.76)$ & \multirow{4}{*}{$\begin{array}{r}0.8363 \\
(\mathrm{NS})\end{array}$} \\
\hline & Primary care & $21(18.92)$ & $3(25.0)$ & $2(15.38)$ & \\
\hline & $\begin{array}{r}\text { Secondary care - Non } \\
A G P \\
\end{array}$ & $25(22.52)$ & $2(16.67)$ & $1(7.69)$ & \\
\hline & $\begin{array}{r}\text { Secondary care - } \\
A G P\end{array}$ & $45(40.54)$ & $5(41.67$ & $6(46.15)$ & \\
\hline
\end{tabular}

Table 2: Association of different characteristics with respondent's feedback $(n=136)$.

*Obtained using Pearson's Chi-square test; NS: Not significant

The performance of the risk assessment tool was similar in all ages, both genders, and in BAME individuals. The association of different characteristics with respondent's feedback on the outcome of risk assessment tool is shown in Table 2. The feedback was expressed as correct, underestimate and overestimate by the respondents. It is evident that the association of age and feedback was statistically insignificant. Similar was the observation for sex and ethnicity. Further, the proportion of different comorbidities across three feedback categories were insignificantly different. The work place setting of respondents had also insignificant association with the feedback. 


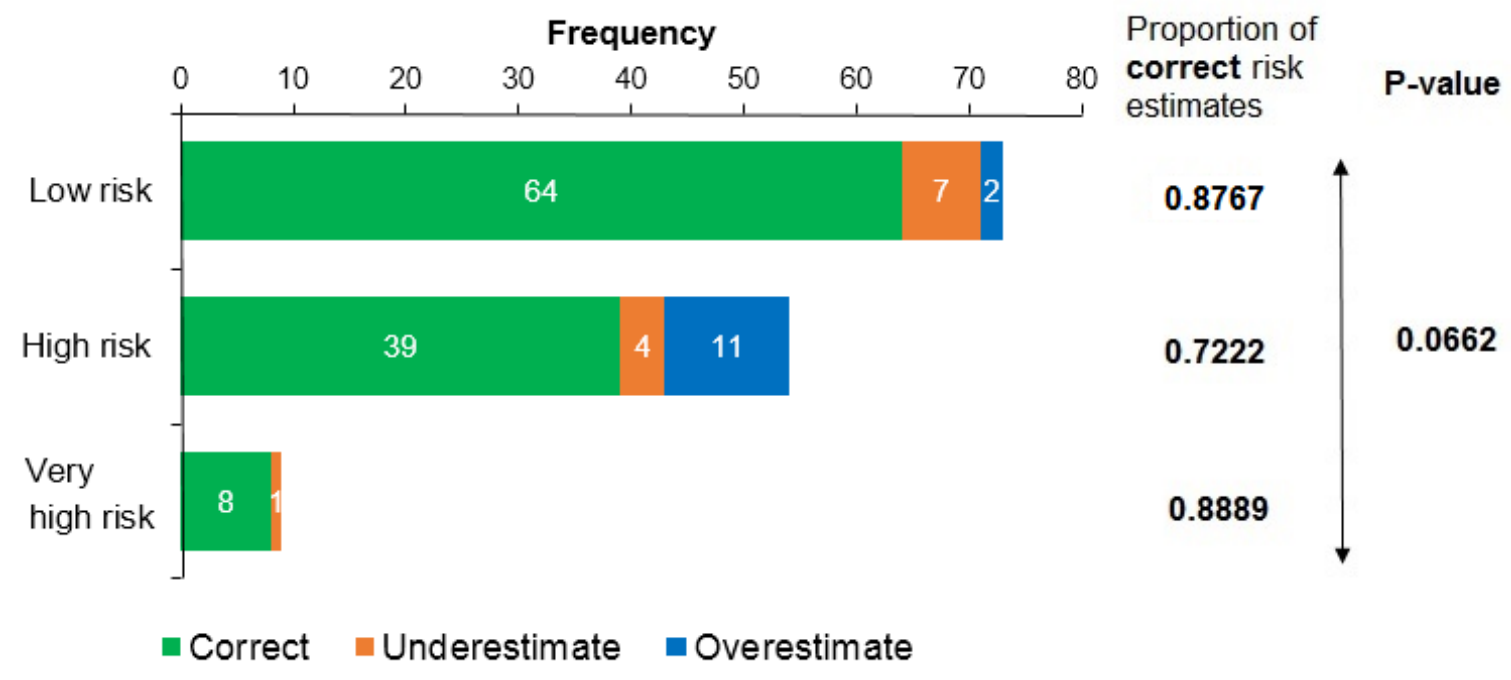

Figure 2: Horizontal bar chart showing distribution of respondents according to their feedback in each risk category.

To assess the bias of respondents towards risk outcomes by the tool, the association between risk levels and respondent's feedback was obtained, which resulted in no significant difference. The proportion of correct risk outcomes as perceived by the respondents was insignificantly different $(p=0.0662)$ across risk categories, as evident from Figure 2 . This revealed that there was no bias of respondents towards any specific risk outcome. 


\begin{tabular}{|c|c|c|c|c|}
\hline \multirow{2}{*}{ Category } & \multirow{2}{*}{ Level } & & \multicolumn{2}{|c|}{ Weighted Kappa coefficient (p-value) } \\
\hline & & $n$ & Scenario I* & Scenario II* \\
\hline Overall & & & $0.803(<0.0001)$ & $0.657(<0.0001)$ \\
\hline \multirow{3}{*}{ Age (years) $)^{*}$} & $<50$ & 75 & $0.739(<0.0001)$ & $0.466(<0.0001)$ \\
\hline & $50-59$ & 41 & $0.725(<0.0001)$ & $0.725(<0.0001)$ \\
\hline & $60-69$ & 16 & $0.614(0.0034)$ & $0.614(0.0034)$ \\
\hline \multirow{2}{*}{ Sex } & Male & 88 & $0.791(<0.0001)$ & $0.753(<0.0001)$ \\
\hline & Female & 48 & $0.806(<0.0001)$ & $0.509(<0.0001)$ \\
\hline
\end{tabular}

Table 3: Kappa Coefficient for agreement between Welsh Risk Assessment Tool Covid-19 and respondent's feedback on risk categorization $(n=136)$.

Agreement level for Kappa coefficient: < 0.20: Poor; 0.21-0.40: Fair; 0.41-0.60: Moderate; 0.61-0.80: Substantial; > 0.80: Almost perfect; $\$ 4$ cases were above 70 years for which coefficient was not obtained

*Scenarios showing respondent's true belief:

\begin{tabular}{|l|l|l|l|}
\hline \multirow{2}{*}{$\begin{array}{l}\text { Respondent's } \\
\text { Feedback }\end{array}$} & \multirow{2}{*}{$\begin{array}{l}\text { WRA tool } \\
\text { Outcome }\end{array}$} & \multicolumn{2}{|c|}{ Respondent's belief } \\
\cline { 2 - 4 } & Low & Scenario I & Scenario II \\
\hline \multirow{3}{*}{ Underestimation } & High & Very high & Very High \\
\cline { 2 - 4 } & Very high & Very high & Very high \\
\hline \multirow{2}{*}{ Overestimation } & High & Low & Lery high \\
\cline { 2 - 5 } & Low & Low & Low \\
\hline
\end{tabular}

Table 3 provides the weighted kappa coefficient, as a measure of agreement between the WRA tool and respondent's feedback. It shows an overall, as well as age and sex specific coefficients and their statistical relevance. The responses by WRA tool were Low, High and Very high. Those who responded as correct were in agreement with the tool outcome. However, for those who believed the outcome as underestimate, the higher risk level was considered as their true belief. For those, who believed the outcome as overestimate, the lower risk level was considered as their true belief. Accordingly, two scenarios were considered as shown in the legend (Table 3). In the first, it was assumed that the true belief of respondents, giving underestimate as feedback, could be high and very high for the tool outcomes low and high respectively. While the true belief for those giving overestimate as feedback, was considered as low. Thus, the respondent's feedback was transformed in terms of three risk levels so as to establish the agreement with the tool.

The overall weighted kappa coefficient for scenario I was $0.803(p<0.0001)$, indicating almost perfect agreement between the tool and the transformed respondent's feedback; while for scenario II, the coefficient was $0.657(p<0.0001)$, indicating substantial agreement. The reduction of 
agreement in scenario II was attributed to the increased extent of disagreement with the tool outcome. This was the minimum possible coefficient for the studied sample.

Subsequently, the coefficients were obtained according to the levels of two fixed factors i.e. age and gender. Under scenario I, all the three age categories showed substantial agreement between the tool and the perception, with younger age group indicating higher agreement as compared to older one. Under scenario II, the extent of disagreement assumed in the youngest group ( $<50$ years) was maximum, resulting into a smaller coefficient (0.466) and thus indicating moderate agreement between the tool and perception. To elaborate, in this age category, there were 7 cases of low risk by the tool, which was perceived as underestimation by them. So for these cases, in scenario l, their true belief was assumed to be high and in scenario II, as very high, thus resulting into lowering of the coefficient in scenario II. There was no change in the extent of disagreement in other two age categories, and therefore the coefficients were unchanged.

As regards sex, under scenario I, the coefficients for both male and female were very close and suggested nearly perfect agreement between the two variables. Under scenario II, there was marginal lowering of coefficient for males (0.753); however, a considerable reduction for females (0.509) due to increased extent of disagreement. Thus, the overall reduction in the coefficient under scenario II was due to higher disagreement of females with age $<50$ years. However, in the extreme scenario, the agreement between the tool and perception was substantial.

\begin{tabular}{|c|c|c|c|c|c|}
\hline \multirow{2}{*}{ Characteristics } & \multirow{2}{*}{ Levels } & \multicolumn{3}{|c|}{ Tool based risk category } & \multirow{2}{*}{ P-value* } \\
\hline & & Low & High & Very High & \\
\hline \multirow{4}{*}{ Age category (in years) } & $<50(\mathrm{n}=61)$ & $51(83.61)$ & $9(14.75)$ & $1(1.64)$ & \multirow{4}{*}{$<0.0001(\mathrm{~S})$} \\
\hline & $50-59(\mathrm{n}=34)$ & $12(35.29)$ & $21(61.76)$ & $1(2.94)$ & \\
\hline & $60-69(\mathrm{n}=12)$ & $1(8.33)$ & $9(75)$ & $2(16.67)$ & \\
\hline & $70-79(n=4)$ & $0(0)$ & $0(0)$ & $4(100)$ & \\
\hline \multirow{2}{*}{ Sex } & Female $(\mathrm{n}=39)$ & $30(76.92)$ & $6(15.38)$ & $3(7.69)$ & \multirow{2}{*}{$0.0034(\mathrm{~S})$} \\
\hline & Male $(\mathrm{n}=72)$ & $34(47.22)$ & $33(45.83)$ & $5(6.94)$ & \\
\hline
\end{tabular}

Table 4: Association of demographic characteristics with risk stratification for respondents in agreement with tool outcome $(n=111)$

*Obtained using Pearson's Chi-square test; S: Significant

Table 4 gives the distribution of respondents with respect to demographic factors and tool based risk stratification. There were 111 respondents who agreed to the risk level suggested by the tool. In other words, the perception of these individuals about their risk level matched with that of the tool. Hence, the purpose of this analysis was to understand the association of risk perception with the levels of different factors. As regards age, a significant association was observed between age and risk classification by the tool $(p<0.0001)$. The respondents below 50 years predominantly believed that they had lower risk (83.61\%); while those in older category felt the risk to be on higher side. This is quite likely because younger age group had hardly any comorbidities. This is in contrast to older age group who had one or more comorbidities. The association of sex and risk stratification was also statistically significant $(p=0.0034)$. Females predominantly believed that they are at low risk of disease $(76.92 \%)$, while $47.22 \%$ and $45.83 \%$ males felt that they were at low and high risk respectively. 


\begin{tabular}{|l|c|c|c|c|c|c|c|}
\hline \multirow{2}{*}{} & \multirow{2}{*}{ Levels } & \multicolumn{3}{|c|}{ Underestimate $(\mathrm{n}=12)$} & \multicolumn{3}{|c|}{ Overestimate $(\mathrm{n}=13)$} \\
\cline { 3 - 9 } & & Male & Female & Total & Male & Female & Total \\
\hline \multirow{3}{*}{ Age category (in years) } & 550 & $4_{(1,2,1)^{*}}$ & $6_{(6,0,0))^{*}}$ & $10_{(7,2,1)^{*}}$ & $2_{(0,2,0)^{*}}$ & $2_{(2,0,0)}$ & $4_{(2,2,0)^{*}}$ \\
\cline { 3 - 9 } & $50-59$ & $1_{(0,1,0)^{*}}$ & $1_{(0,1,0)^{*}}$ & $2_{(0,2,0) *}$ & $5_{(0,5,0)^{*}}$ & 0 & $5_{(0,5,0)^{*}}$ \\
\cline { 2 - 9 } & $60-69$ & 0 & 0 & 0 & $4_{(0,4,0)^{*}}$ & 0 & $4_{(0,4,0)^{*}}$ \\
\hline Total & & $5_{(1,3,1)^{*}}$ & $7_{(6,1,0)^{*}}$ & $\mathbf{1 2}$ & 11 & 2 & $\mathbf{1 3}$ \\
\hline
\end{tabular}

Table 5: Cross tabulation using non-modifiable risk factors for respondents disagreeing to risk classification $(n=25)$

*(Low, High, Very high risk)

Table 5 shows the cross tabulation based on age and sex for respondents who either felt underestimation (12) or overestimation (13) of risk by the tool. Out of 12 respondents in the first category, majority i.e. 10 were $<50$ years of age with 6 females and 4 males. Table shows that all females were categorised as low by the tool, however, they believed that the risk could be higher. Similarly, 3 males believed that the risk could be higher than estimated by the tool. Thus, even though there were lesser comorbidities in this age group, leading to low scores and thereby lower risk, their perceived risk was higher. This revealed that there could be some more factors contributing to their perception, which are not part of the risk assessment tool.

In the overestimation category, 11 respondents were male, who believed that their risk was overestimated by the tool. Nine of these individuals were from elderly category ( $>50$ years) and scored high due to their comorbid conditions. Despite, they perceived a lower risk. Perhaps, the current comorbidity status of these respondents could be better, which influence their risk perception.

Following the initial feedback, the tool was rolled out in Wales across all public sectors and has been used extensively with an estimated 100,000 healthcare professionals and public/private sector workers using it. 3728 out of these returned a follow up questionnaire about the concordance between the tool and their own risk perception, Figure 3.

Figure 3: Concordance between Tool and self-perception of risk

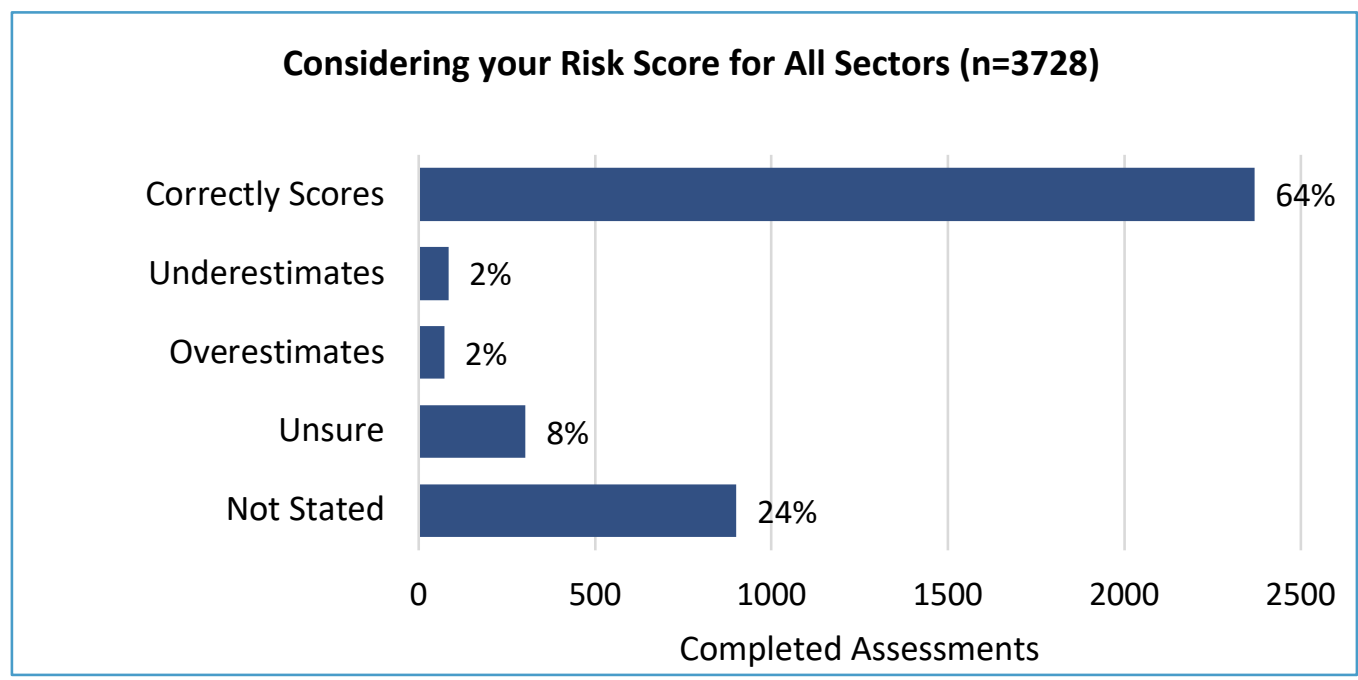


If those stating "unsure" and "not stated" are taken out, a total of 2525 respondents either stated that the tool was in concordance with their own risk perception or over or underestimated their risk.

93.8\% of these respondents (2369 out of 2525) felt that the All Wales Covid-19 Risk Assessment Tool correctly identified their risk and was in concordance with their own risk perception, thereby giving the staff the confidence to believe in the tool and the mitigating actions it signposted.

\section{DISCUSSION}

We present the findings of the initial experience of use of the All Wales COVID-19 risk assessment tool (WRA tool). Our statistical analyses of the results from the initial cohort 136 valid responses indicates that there was broad agreement amongst survey respondents with the WRA tool risk assessment. The risk assessment outcomes were also not biased towards particular outcomes based on respondent demographic factors.

In participants where there was disagreement with the risk assessment outcome, this was not biased towards a specific participant demographic factor such as age, sex, workplace setting, or co-morbidity status. Notably, a higher proportion of participants assigned to the 'high risk' category by the tool disagreed with this finding and felt they should be considered lower risk. This aligns with the purposes of this risk assessment tool in favouring a more cautious assessment response. This can help facilitate a workplace response to the tool assessment, which is tailored to individual factors that can reflect lower risk not captured by the tool.

Greater numbers of participants who felt the tool underestimated risk were $<50$ years old, which is likely to reflect these respondent's having other co-morbidities not captured by the tool. A greater proportion of the participants who felt the tool overestimated their risk were $>50$ years old, which may be due to personal perceptions of the contributions of their risk factors to poor prognosis or circumstances such as improved comorbidity status e.g. better diabetic control.

While we have not done a detailed statistical analysis of the responses from the larger cogort of 3728 responses from the All Wales roll out of the tool, it is obvious at the first glance that the results are in line with our statistical analysis with 93.8\% expressing confidence in the concordance between the risk assessment calculated by the tool and their own risk perception.
Future refinement of the WRA tool could follow from further understanding of the specific factors influencing COVID-19 risk. Our tool included sickle cell trait, and haemoglobinopathies such as thalassaemia trait or disease as a risk factor based on expert consensus given and findings of disseminated clotting in post mortem studies of COVID-19 patients ${ }^{12,13}$. Further observational data regarding the mortality of patients with haemoglobinopathies such as thalassaemia who develop COVID-19 will help inform the continued inclusion of this factor. In addition as high quality longitudinal observational studies become available, the inclusion of further relevant risk factors may be indicated. Down's Syndrome is one such risk factor which has become increasingly evident ${ }^{14}$, thus has now been added within updated guidance notes of the WRA tool.

Risk assessment tools are necessary to help provide a guide for staff working in at risk positions. A disadvantage of all risk tools is the lack of specific recommendations based on risk scoring outcomes. The WRA is the only one available amongst the four nations of the UK to provide a mitigation framework based on the risk scoring. As the influence of co-morbidities on modifying COVID-19 disease outcomes is further understood, the specific recommendations of the WRA tool for workplace changes can be modified to reduce risk of disease spread whilst safely mitigating the economic impact. In addition, the recommendations of the tool can in future be modified based on regional epidemiological factors such as local positive SARS-CoV-2 antibody status, and regional COVID-19 prevalence to allow the tool to be further utilised as the spread of COVID-19 fluctuates in the coming months with increasing uptake of SARSCoV-2 vaccinations ${ }^{15,16}$.

As of the date of submission of this paper, Scotland and England have released their own versions of the risk assessment tool for Covid-19 17,18 , but the Welsh tool remains the only one which is self-administered and guides the user to 
a mitigation strategy to protect them from getting severe Covid-19 infection.

\section{CONCLUSIONS}

We believe risk assessments are needed to identify and protect vulnerable populations at risk of worse outcomes during a pandemic, as seen with our experience administering the AllWales COVID-19 Risk Assessment Tool. Our results demonstrate a high concordance between tool user's perceived risk and risk assessment tool risk stratification. Of those who disagree with the tool, the majority felt that their risk was lower than that identified by the tool, thus favouring the more cautious and thereby safe assessment intended. We believe that this tool is appropriate in identifying risk for both health care workers and the public.

The tool is based on a common sense approach of combining advancing age, sex and comorbidities and presenting a self-administered tool providing a risk matrix which can in future be adapted for any similar illness. Its wide acceptance in wales with the roll out to all public sector employees provides a framework for a similar approach for public health emergencies in the future.

\section{REFERENCES}

1. Understanding excess mortality: comparing COVID-19's impact in the UK to other European countries | The Health Foundation. Accessed December 11, 2020. https://www.health.org.uk/news-andcomment/charts-and-infographics/comparingcovid-19-impact-in-the-uk-to-europeancountries

2. Zhou F, Yu T, Du R, et al. Clinical course and risk factors for mortality of adult inpatients with COVID-19 in Wuhan, China: a retrospective cohort study. Lancet. 2020;395(10229):10541062. doi:10.1016/S0140-6736(20)30566-3

3. Coronavirus (COVID-19) related deaths by ethnic group, England and Wales - Office for National Statistics. Accessed November 21, 2020.

https://www.ons.gov.uk/peoplepopulationandc ommunity/birthsdeathsandmarriages/deaths/arti cles/coronavirusrelateddeathsbyethnicgroupeng landandwales/2march2020to10april2020

4. Coronavirus-related deaths by ethnic group, England and Wales methodology - Office for National Statistics. Accessed June 10, 2020. https://www.ons.gov.uk/peoplepopulationandc ommunity/birthsdeathsandmarriages/deaths/met hodologies/coronavirusrelateddeathsbyethnicgr oupenglandandwalesmethodology

5. Ethnic minority deaths and Covid-19 | The King's Fund. Accessed November 21, 2020. https://www.kingsfund.org.uk/blog/2020/04/eth nic-minority-deaths-covid-19

6. Platt L, Warwick R. Are Some Ethnic Groups More Vulnerable to COVID-19 than Others? Accessed November 21, 2020. www.nuffieldfoundation.org.

7. Coronavirus Risk Assessment Tool For People Who Work in Health and Social Care in Wales.

8. ICNAR report on covid 19. ICNARC_covid 19 report 2020. 2020;(May):1-26.

9. Docherty $A B$, Harrison EM, Green $C A$, et al. Features of 16,749 hospitalised UK patients with COVID-19 using the ISARIC WHO Clinical Characterisation Protocol. IS Nguyen-Van-Tam. 10. doi:10.1101/2020.04.23.20076042

10. Risk Assessment. Accessed November 21, 2020. https://design.developmentoverview.com/pwa/B APIO_COVID19RiskAssessmentTool/index.html $? d=22072020$

11. COVID-19 workforce risk assessment tool GOV.WALES. Accessed November 21, 2020. https://gov.wales/covid-19-workforce-riskassessmenttool?_ga=2.163614911.1815841523.15909380 06-184063354.1584523019

12. View of Implications of SARSr-CoV 2 infection in thalassemias: Do patients fall into the "high clinical risk" category? Accessed November 21, 2020.

https://www.mattioli1885journals.com/index.ph p/actabiomedica/article/view/9592/8762

13. Rapkiewicz A V., Mai X, Carsons SE, et al. Megakaryocytes and platelet-fibrin thrombi characterize multi-organ thrombosis at autopsy in COVID-19: A case series. EClinicalMedicine. 2020;24:100434.

doi:10.1016/j.eclinm.2020.100434

14. Clift AK, Coupland CAC, Keogh RH, Hemingway H, Hippisley-Cox J. COVID-19 Mortality Risk in Down Syndrome: Results From a Cohort Study Of 8 Million Adults. Ann Intern Med. Published online October 21, 2020. doi:10.7326/m204986

15. Tregoning JS, Brown ES, Cheeseman HM, et al. Vaccines for COVID-19. Clin Exp Immunol. 2020;202(2):162-192. doi:10.1111/cei.13517

16. Different COVID-19 Vaccines | CDC. Accessed December 11, 2020. https://www.cdc.gov/coronavirus/2019ncov/vaccines/different-vaccines.html

17. What to Include in Your COVID-19 Risk Assessment.

18. Coronavirus (COVID-19): guidance on individual risk assessment for the workplace gov.scot. Accessed December 11, 2020. https://www.gov.scot/publications/coronaviruscovid-19-guidance-on-individual-riskassessment-for-the-workplace/ 


\section{All Wales COVID-19 Workforce Risk Assessment Tool - confidential once completed}

\section{How to use this Tool}

The Tool asks a number of questions about you that are designed to identify whether you are at a higher risk from Covid-19. It asks some questions about your health, weight and ethnicity which may increase your risk of serious illness following an infection with Covid-19.

You may know the answers to the questions yourself, but if not you can discuss this with your line manager, workforce team, union representative, Occupational Health or advocate.

You may also want to consult your GP about the health conditions that are listed.

Please complete the questions and add up your score.

COVID-19 Understand your risk: Act to stay safe

We will continue to develop and improve the All Wales COVID-19 Workforce Risk Assessment Tool. If you have any comments or queries on the use or to improve the tool please email HSS.Covid19.WorkplaceAssessmentSubGroup@gov.wales

\section{All Wales COVID-19 Workforce Risk Assessment Tool - confidential once completed}

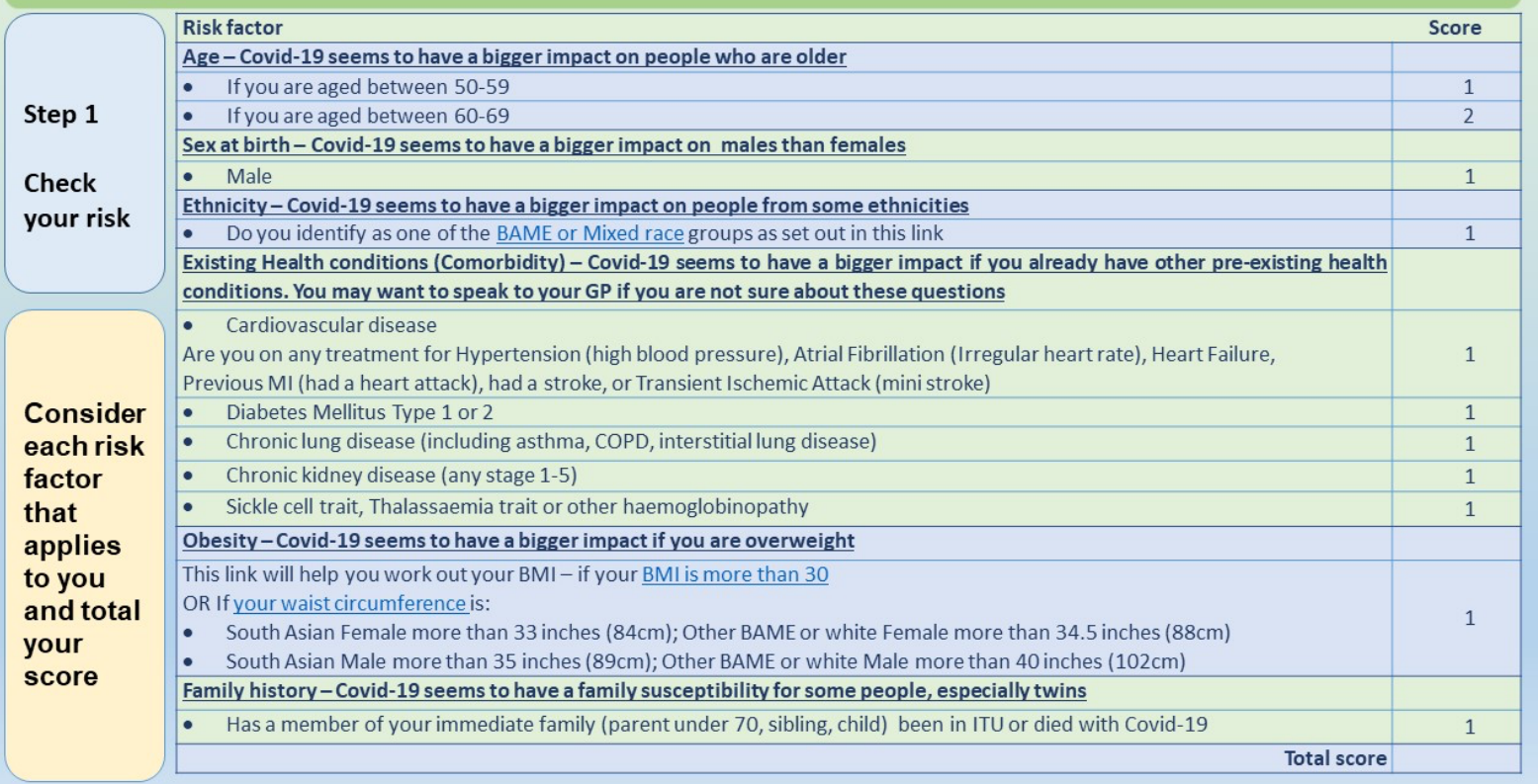




\section{All Wales COVID-19 Workforce Risk Assessment Tool - confidential once completed}

Step 2 Understand your risk - what your score means in your workplace setting

\begin{tabular}{|c|c|c|c|}
\hline & Score & & \\
\hline Workplace setting & Low Risk 0-3 & High Risk 4-6 & Very High Risk 7 or more \\
\hline Community care & $\begin{array}{l}\text { Continue with } \\
\text { caution }\end{array}$ & $\begin{array}{l}\text { Consider modified duties } \\
\text { and PPE Review* }\end{array}$ & Work from home or non patient facing \\
\hline Primary care & $\begin{array}{l}\text { Continue with } \\
\text { caution }\end{array}$ & $\begin{array}{l}\text { Consider modified duties } \\
\text { and PPE Review* }\end{array}$ & Work from home or non patient facing \\
\hline $\begin{array}{l}\text { Secondary care } \\
\text { Non AGP }\end{array}$ & $\begin{array}{l}\text { Continue with } \\
\text { caution }\end{array}$ & $\begin{array}{l}\text { Consider modified duties } \\
\text { and PPE Review* }\end{array}$ & Work from home or non patient facing \\
\hline $\begin{array}{l}\text { Secondary care } \\
\text { with AGP }\end{array}$ & PPE Review* & $\begin{array}{l}\text { Redeploy out of Aerosol } \\
\text { Generating Procedure areas }\end{array}$ & Work from home or non patient facing \\
\hline
\end{tabular}

*PPE Review - This should consider the work setting, review all Transmission Based Precautions and ensure the selection and correct use of PPE including training and fit testing.

Now arrange a time to discuss with your line manager to agree a plan and ensure you are appropriately protected. This may include a discussion with Occupational Health.

\section{All Wales COVID-19 Workforce Risk Assessment Tool - confidential once completed}

Step 3 Identify the right actions for you

Now you have completed yourCOVID-19 Risk Assessment score please discuss with your line manager, occupational health, workforce team, union representative or advocate to ensure you are appropriately protected.

\section{Things I can do myself}

Do the important things to maintain your safety in the workplace

- Observe good hand hygiene, with frequent use of soap and water or alcohol-containing gel.

- Maintaining a distance of 2 metres is an important aspect of the measures we must all take to minimise the risks of the spread of COVID 19. It is something we should aim to do in all aspects of our daily lives and anywhere in work where this is possible.

- Use appropriate personal protective equipment identified for your role and know how to use it properly.

- Observe isolation requirements for known or suspected COVID-19 cases.

- Ensure your infection control training is up to date.

\section{Things my employer can help with}

- Your line manager or union rep will help you use the tools and identify the right actions for you.

- Making adjustments

$>$ Can some or all of your duties be undertaken or completed in a different way

- Can adjustments be made to enable you to work safely,

$>$ Can face-to-face contact with the public and home visits be limited or avoided

$>$ Ensure appropriate physical distancing within the workplace - Will adjustments allow you to work from home

- If no adjustments can be made to mitigate your risk then temporary Medical Exclusion may be considered. 


\section{All Wales COVID-19 Workforce Risk Assessment Tool - confidential once completed}

Step 4 Act now - take the right actions

Following your discussions with your line manager record the agreed plan and ensure you set a time for review.

What reasonable adjustments have been identified and taken to mitigate your identified risks?

Date for review

Date adjustments were introduced*

This may be time based or instigated by an event that impacts on your circumstances

\section{All Wales COVID-19 Workforce Risk Assessment Tool - confidential once completed}

Welsh Government are committed to ensuring that we learn quickly so that we can best protect you from harm due to COVID-19.

Your help and support in consenting to us gathering the evidence from your risk assessment is vital to inform further analysis so that we can better understand the disproportionate impact that COVID-19 is having on some individuals. This information will be used for this sole purpose in relation to COVID-19 and to continue to improve our risk assessment. It will only ever be your anonymised information that will be shared.

Information provided in confidence will only be used for the purposes advised and consented to by yourself

COVID-19 Understand your risk: Act to stay safe

We will continue to develop and improve the All Wales COVID-19 Workforce Risk Assessment Tool. If you have any comments or queries on the use or to improve the tool please email HSS.Covid19.WorkplaceAssessmentSubGroup@gov.wales 